\title{
Suppression of Human Coronavirus 229E Infection in Lung Fibroblast Cells via RNA Interference
}

\author{
Hamidreza Montazeri Aliabadi ${ }^{1,2 *}$, Jennifer Totonchy ${ }^{1}$, Parvin Mahdipoor ${ }^{1}$, \\ Keykavous Parang ${ }^{1,2 *}$ and Hasan Uludag ${ }^{3,4,5 *}$
}

${ }^{1}$ Department of Biomedical and Pharmaceutical Sciences, Chapman University School of Pharmacy, Harry and Diane Rinker Health Science Campus, Irvine, CA, United States, ${ }^{2}$ Center for Targeted Drug Delivery, Chapman University School of Pharmacy, Harry and Diane Rinker Health Science Campus, Irvine, CA, United States, ${ }^{3}$ Department of Chemical and Material Engineering, University of Alberta, Edmonton, AB, Canada, ${ }^{4}$ Faculty of Pharmacy and Pharmaceutical Sciences, University of Alberta, Edmonton, $A B$, Canada, ${ }^{5}$ Department of Biomedical Engineering, Faculty of Medicine and Dentistry, University of Alberta, Edmonton, $A B$, Canada

\section{OPEN ACCESS}

Edited by:

Themis Prodromakis,

University of Southampton,

United Kingdom

Reviewed by: Jessica Rouge,

University of Connecticut, United States

Dinesh Devadoss,

Florida International University,

United States

*Correspondence: Hamidreza Montazeri Aliabadi montazer@chapman.edu

Keykavous Parang parang@chapman.edu Hasan Uludağ huludag@ualberta.ca

Specialty section: This article was submitted to Biomedical Nanotechnology, a section of the journal Frontiers in Nanotechnology

Received: 21 February 2021 Accepted: 12 April 2021 Published: 27 April 2021

Citation:

Montazeri Aliabadi H, Totonchy J, Mahdipoor $P$, Parang $K$ and Uludağ $H$

(2021) Suppression of Human Coronavirus 229E Infection in Lung Fibroblast Cells via RNA Interference.

Front. Nanotechnol. 3:670543.

doi: 10.3389/fnano.2021.670543
Despite extensive efforts to repurpose approved drugs, discover new small molecules, and develop vaccines, COVID-19 pandemic is still claiming victims around the world. The current arsenal of antiviral compounds did not perform well in the past viral infections (e.g., SARS), which casts a shadow of doubt for use against the new SARS-CoV-2. Vaccines should offer the ultimate protection; however, there is limited information about the longevity of the generated immunity and the protection against possible mutations. This study uses Human Coronavirus 229E as a model coronavirus to test the hypothesis that effective delivery of virus-specific siRNAs to infected cells will result in lower viral load and reduced cell death. Two different categories of nucleic acid delivery systems, Peptide/Lipid-Associated Nucleic Acids (PLANAs) and lipophilic polymers, were investigated for their toxicity in human lung fibroblast cells and their ability to deliver specific siRNAs targeting Spike and Envelope proteins in order to prevent cell death in infected cells. Selected siRNAs were effectively delivered to human lung fibroblast cells with negligible toxicity. Cell death due to viral infection was significantly reduced with individual and combinatorial silencing of selected viral proteins. The combinatorial silencing of Spike and Envelope proteins restored the cell viability completely and eliminated plaques in the investigated system. Our cell culture data indicate promising results for the RNAi based approach as an alternative antiviral treatment.

Keywords: coronavirus, RNA inteference, lung fibroblast cell, delivery, PLANA

\section{INTRODUCTION}

COVID-19 is an emerging disease with little history of therapeutic development. The previous experience with other viral epidemics such as SARS and MERS have revealed difficulties associated with the treatment of similar viral infections. Based on our analysis of the current activity, the researchers are pursuing the two main approaches to manage the current epidemic. On one hand, small molecular drugs are being extensively explored to repurpose them for the treatment of SARS$\mathrm{CoV}-2$. It is hoped that certain pre-approved drugs will prevent the replication of SARS-CoV-2 and will be widely available since they are approved for human use. It is likely that effective drug hits will emerge from this activity [in one of the first published studies, 29 FDA-approved drugs were 
identified as "hits" based on their protein interactions maps (Gordon et al., 2020)]. Some of the existing antiviral compounds may also be promising. However, the current arsenal of antiviral compounds based on small molecular drugs has been mostly ineffective in the past viral infections (indicated by lack of FDA-approved drugs for treatment of those infections). Thus, there is a chance that the approved drugs will not be effective against the new SARS-CoV-2. Some high-profile drugs are already failing in initial studies [e.g., hydroxychloroquine (Cavalcanti et al., 2020; Lyngbakken et al., 2020)], and no obvious candidates are emerging. Even remdesivir, which showed promising results in vitro, has failed to produce a statistically significant difference in the clinical status of COVID19 patients compared to standard care in large clinical studies (Spinner et al., 2020; Wang et al., 2020). However, the FDA authorized remdesivir for COVID-19 treatment on October $22^{\text {nd }}$, 2020, under emergency use (U.S. Food and Drug Administration). Also, vaccines are being extensively explored since they could offer ultimate protection against the SARS-CoV2 infection. One can inject a viral protein, the attenuated virus, or DNA/mRNA coding for viral proteins, and induce immunity against the virus. Despite the fact that there were no vaccines available against any of the coronavirus epidemics in the past (e.g., SARS or MERS; which could be largely due to more limited outbreak), mRNA vaccines against the SARS-CoV-2 from PfizerBioNTech and Moderna have been recently authorized for emergency use in the United States and other countries. Although more extensive studies are underway, the current evidence suggests that the immune response generated by these vaccines seems durable and initial protection is readily observed in clinical studies. Long term immunity remains to be investigated since it is still early days of vaccine use at the time this study is conducted. Moreover, the global dissemination of SARSCoV2 is extensive enough that, even with highly effective vaccines and good vaccine uptake, vaccination will not be sufficient to eliminate clinically relevant infections in the short-term. Thus, there is still urgent need for therapeutic agents to mitigate the virus pathogenesis and minimize physiological damage in infected patients.

Using RNAi approaches as an antiviral strategy is not unprecedented. Past experiences with SARS have indicated the efficiency of siRNA therapy as a potential antiviral approach. In 2005, Wu et al. reported that siRNAs targeting spike protein (S-protein) of SARS-CoV cause $85-90 \%$ reduction in viral load as assessed by PCR analysis (Wu et al., 2005). The efficiency of this approach has also been verified by using short hairpin RNAs (shRNA) against SARS-CoV (Qin et al., 2004; Zhang et al., 2004). RNA-dependent RNA polymerase (RDRP) (Meng et al., 2006), nucleocapsid (N-protein) (Zhao et al., 2005), envelope (E-protein) (Meng et al., 2006), and membrane (M-protein) (Qin et al., 2007) are among other targets explored in SARS$\mathrm{CoV}$ infection with different degrees of success. In separate studies screening 48 siRNAs targeting different regions of SARS-CoV genome, S-protein, and open reading frame $1 \mathrm{~b}$ (ORF1b) were identified as effective siRNAs against the viral infection and further validated in Rhesus macaque primates ( $\mathrm{Li}$ et al., 2005; Tang et al., 2008; Uludağ et al., 2020).
Developing RNAi-based drugs for SARS-CoV-2 is likely to offer more specific therapies and can potentially be directed against two different categories of targets: 1) viral proteins essential in survival and replication of SARS-CoV-2, and 2) host factors involved in cellular entry and trafficking of the virus. We recently reviewed these RNAi-based strategies and their prospect in COVID-19 treatment in (Uludağ et al., 2020). Herein, we report on the former approach due to a lower chance of complications that could result from silencing host proteins and controversy over the efficiency of targeting proteins such as angiotensin-converting enzyme 2 (ACE2). We have previously reported efficient small interfering RNA (siRNA) delivery to cancer cells via specifically designed polymers (Aliabadi et al., 2011; Aliabadi et al., 2013; Aliabadi et al., 2020) and cell-penetrating peptides (Do et al., 2017; Mozaffari et al., 2019). We also recently reported a novel delivery system called Peptide/Lipid-Associated Nucleic Acids (PLANAs), which is based on the incorporation of specifically designed cell-penetrating peptides in a multi-component nanoparticle (Hall et al., 2021a) (United States patent application number 17170785). The structure of the peptides and the proposed structure of PLANAs (and how they encapsulate nucleic acids) are presented in Supplementary Figures S1, S2, respectively. In this study, we evaluated the safety of these two siRNA carriers in human lung fibroblast cells, the efficiency of the carriers in internalizing the siRNA into these cells, and the efficiency of this approach in minimizing Human Coronavirus 229E-induced cell death and plaque formation.

\section{MATERIALS AND METHODS}

\section{Materials}

Lipofectamine $^{\mathrm{TM}} \quad 2000$ was purchased from Life Technologies (Grand Island, NY, United States). 1,2Dioleoyl-sn-glycero-3-phosphoethanolamine (DOPE), 1,2dioleoyl-3-trimethylammonium-propane (DOTAP; chloride salt), cholesterol, phosphatidylcholine, and Avanti Mini Extruder were provided by Avanti Polar Lipids, Inc. (Alabaster, AL, United States). Cell Counting 8 (CCK8) KIT was obtained from Biotool (Houston, TX, United States; also known as WST-8). VECTASHIELD VIBRANCE with DAPI (used to stain the cell nuclei) was obtained from Vector Laboratories (Burlingame, CA, United States). All other reagents and consumables, including cell culture requirements and Texas Red (used to stain cell membrane) were provided by VWR (Radnor, PA, United States).

All Stars negative control siRNA labeled with Alexa Fluor 488 (AF488; Catalogue number 1027292; sequence: proprietary) was purchased from Qiagen (Valencia, CA, United States). The siRNAs targeting spike (S) and envelope (E) proteins were designed based on the viral RNA sequence reported in literature (Raabe et al., 1990; Zhang et al., 2014) using the Integrated DNA Technologies (IDT) primer design software and were provided by IDT with the following sequences: 
Spike protein: Forward - $5^{\prime}$-GUU AAA UUU GGC AGU GUA UGU UUU UCG-3'

Reverse - $5^{\prime}$-CGA AAA ACA UAC ACU GCC AAA UUU AAC-3'

Envelope protein: Froward $-5^{\prime}$ GUU AAA UUU GGC AGU GUA UGU UUU UCG- $3^{\prime}$

Reverse - 5'CGA AAA ACA UAC ACU GCC AAA UUU AAC- $3^{\prime}$

\section{Methods}

\section{Carriers}

The polymeric carrier used in this study was LeuFect B (batch numbers 12-18-6A and 12-18-9A) from RJH Biosciences (Edmonton, Canada). The components and preparation methods for PLANAs have been previously reported (Hall et al., 2021a). Briefly, PLANA nanoparticles were prepared by incorporating siRNA(s) and linear $\mathrm{R}_{5} \mathrm{~K}_{2}$ peptide-stearic acid conjugate (LPC18) into the selected lipid composition. The peptide and siRNA were mixed in the aqueous portion of the formulation, while 1,2-dioleoyl-sn-glycero-3-phosphoethanolamine (DOPE), cholesterol, and phosphatidylcholine were mixed in ethanol. The two portions were mixed, and PLANA nanoparticles were formed by passing the mixture through an Avanti Mini Extruder (Alabaster, Alabama) with a $100 \mathrm{~nm}$ membrane filter 50 times to create nanoparticles with the approximate size of $100 \mathrm{~nm}$.

\section{Cell Line}

Human MRC-5 lung fibroblast cells (ATCC ${ }^{\circledast}$ CCL-171 ${ }^{\mathrm{TM}}$ ) were thawed and subcultured using Dulbecco's Modified Eagle Medium (DMEM) low glucose. Cells were incubated in $37^{\circ} \mathrm{C}$ and $5 \% \mathrm{CO}_{2}$ for the entire growth time. Cells were expanded when reached $\sim 80 \%$ confluency and were replaced after 30 expansions or 90 days (whichever earlier).

\section{hCoV-229E Virus Preparation}

Human Coronavirus 229E was obtained from ATCC (VR-740). The commercial stock was used to infect MRC-5 cells and initially amplified via two rounds of supernatant transfer (p1 and $\mathrm{p} 2$ ). $50 \mathrm{ml}$ of $\mathrm{p} 2$ supernatant was retained as a seed stock. Final virus stock for experiments was produced by infecting $5 \times \mathrm{X}$ T-185 flasks of MRC- 5 cells with $1 \mathrm{ml}$ each of $\mathrm{p} 2$ seed stock in DMEM+2\% FBS. Infection was allowed to proceed for 5 days until $90 \%$ of MRC- 5 cells showed cytopathic effect. Culture supernatant was collected, and cell material was pelleted via centrifugation at $1000 \times \mathrm{g}$ for $15 \mathrm{~min}$. The clarified supernatant was kept on ice. Fresh serum-free DMEM was added to the culture vessels, and remaining cells were harvested using a cell scraper and pelleted as above. The two cell pellets were combined in a total of $5 \mathrm{ml}$ of serum-free DMEM and subjected to three rapid freeze-thaw cycles. Cell lysates were added back to the clarified culture supernatant, and $1 \mathrm{ml}$ aliquots of virus preparation were stored at $-80 \mathrm{C}$ for experiments. $\mathrm{p} 3$ stock virus was quantitated via $\mathrm{TCID}_{50}$ method on MRC5 cells using the MTT assay described below.

\section{Cytotoxicity}

MRC- 5 cells were seeded in 96 -well plates at $\sim 50 \%$ confluency $24 \mathrm{~h}$ before the experiment. The study groups included: No
Treatment (NT; normal saline) and scrambled siRNA delivered by Leu-Fect B (12-18-6A and 12-18-9A), Lipofectamine $^{\mathrm{TM}}$ 2000, and PLANAs. The siRNA/ Lipofectamine $^{\mathrm{TM}}$ complexes and siRNA/polymer polyplexes were prepared according to the manufacturers guidelines. Briefly, Lipofectamine ${ }^{\mathrm{TM}}$ and siRNA were diluted in FBS- and antibiotic-free OPTIMEM and were mixed. After $20 \mathrm{~min}$. incubation at ambient temperature, the cell culture medium was removed, and the siRNA complexes were added to the wells in OPTIMEM. After $6 \mathrm{~h}$ of incubation at $37^{\circ} \mathrm{C}$, the complexes were removed, and the cell culture medium was added to the wells. For polyplexes, polymer and siRNA were mixed in normal saline, and after 30 min of incubation in ambient temperature, the polyplexes were added to the cells. For each carrier, siRNA was delivered at two final concentrations (in triplicates): 50 and $100 \mathrm{nM}$, which also showed exposure to two different carrier concentrations. Cells were incubated in $37 \mathrm{C}$ and $5 \% \mathrm{CO}_{2}$ for $48 \mathrm{~h}$ after exposure. A Cell Counting 8 (CCK8) KIT (also known as WST-8) was used to evaluate the potential toxicity of the formulations on the viability of the MRC5 cells. After the $24 \mathrm{~h}$ incubation period, $10 \mathrm{uL}$ of CCK solution (Cat. \#B34304) was added to each well. The plates were incubated at $37 \mathrm{C}$ for $1 \mathrm{~h}$, after which the absorbance was measured at $450 \mathrm{~nm}$ using a SpectraMax M5 UV VIZ Plate Reader to determine the percentage of viable cells compared to the no treatment group (after eliminating the signal from "Blank" wells containing cell-less medium with CCK-8 solution added).

\section{Cellular Internalization}

MRC- 5 cells were seeded in 24 -well plates at $~ 50 \%$ confluency the day before the experiment and were treated with one of the following study groups: Normal saline (no treatment; NT), free AF488-siRNA, AF488-siRNA/polymer complexes, PLANA encapsulated AF488-siRNA, or Lipofectamine ${ }^{\mathrm{TM}} 2000$ encapsulating AF488-siRNA (all in triplicates). The final concentration of delivered siRNA was $36 \mathrm{nM}$ for all treatment groups. After exposure to siRNA, cells were incubated at $37^{\circ} \mathrm{C}$ and $5 \% \mathrm{CO}_{2}$ for $24 \mathrm{~h}$, and then the media was removed, and the cells were detached using $0.05 \%$ trypsin (for Lipofectamine the manufacturer's protocol was followed). Trypsinized cells were fixed using 3.7\% formaldehyde in $1 \mathrm{X}$ PBS, and each sample was evaluated using FACSVERSE flow cytometer (BD Biosciences; San Jose, CA). The fluorescein isothiocyanate (FITC) channel was used to quantify cell-associated fluorescence. The percentage of cells positive for fluorescence signal and the mean fluorescence of the cell population were calculated following each flow cytometry analysis using the calibration of the signal gated with No Treatment cells in order to eliminate autofluorescence of approximately $1 \%$ of the population in "no treatment" group.

\section{Confocal Microscopy}

A sterile cover lip was placed at the bottom of each well in 6-well plates, and the cover slips were covered with a $10 \%$ FBS solution in DMEM and were incubated for $30 \mathrm{~min}$ at $37 \mathrm{C}$ to enhance the cell adherence to the cover slip surface. MRC- 5 cells were then seeded in the wells at a confluency of $\sim 70 \%$ and were incubated overnight at $37 \mathrm{C}$ and $5 \% \mathrm{CO}_{2}$. Cells were then treated with one of 
the following groups: free AF488-siRNA, Lipofectamine ${ }^{\mathrm{TM}} 2000$ encapsulating AF488-siRNA, AF488-siRNA/polymer complexes, or PLANA encapsulated AF488-siRNA (all in triplicates). Cells were then incubated for 24 at $37 \mathrm{C}$ and $5 \% \mathrm{CO}_{2}$, after which the media was removed, and cells were washed three times with one $\mathrm{X}$ PBS. Cells were then fixed with 3.7\% formaldehyde in $1 \mathrm{X}$ PBS for $10 \mathrm{~min}$. The fixed cells were rinsed three times in 1X PBS for $5 \mathrm{~min}$, after which Texas Red Phalloidin solution $(40 \mathrm{uL}$ and $10 \mathrm{mg}$ BSA in $10 \mathrm{ml}$ of $1 \mathrm{X}$ PBS) was added to the cells to stain the cell membrane. Stained cells were incubated at room temperature for $1 \mathrm{~h}$, and were then washed three times with $1 \mathrm{X}$ PBS for $5 \mathrm{~min}$. One drop of VECTASHIELD VIBRANCE with DAPI was added to each slide to stain the nucleus, and the coverslips were placed face down on slides, without air bubbles, and were stored overnight away from light to dry. Once dry, a Nikon A1R high-definition resonant scanning confocal microscope and a NIS-Elements software (AR 4.30.02, 64bit) were used to image the cells.

\section{hCoV-229E Inhibition via MTT Assay}

The antiviral studies were performed to test the efficacy of targeting spike and envelope proteins individually and simultaneously, to investigate the potential benefit of combinatorial silencing of two viral targets via delivering a cocktail of siRNAs. For this set of studies, remdesivir was used as a positive control, and media only was used as a negative control. Polymer/siRNA complexes or PLANAs were prepared to deliver $100 \mathrm{nM}$ of siRNA targeting mRNA sequence for spike protein expression, $100 \mathrm{nM}$ of siRNA targeting mRNA sequence for envelope protein, or a combination of $50 \mathrm{nM}$ of each siRNA. Treatments were added to the plate at $1 \mathrm{~h}$ prior to infection. P3 virus stock was added at $2 \mathrm{TCID}_{50}$ units per well in a total of $100 \mu \mathrm{L}$ of serum-free DMEM and incubated at $37 \mathrm{C}$ for one hour. After the initial incubation, an additional $100 \mu \mathrm{L}$ of DMEM containing $4 \%$ FBS was added to each well to make a final concentration of $2 \% \mathrm{FBS}$ and incubated at $37 \mathrm{C}, 5 \% \mathrm{CO} 2$. At 7 days post-infection, cell viability was assessed using MTT assay (Promega) according to manufacturer instructions. Briefly, media was removed and discarded to leave $100 \mu \mathrm{L}$ in each experimental well. MTT reagents were mixed and added directly to cultures (20 $\mu \mathrm{L} /$ well) and allowed to incubate for $1 \mathrm{~h}$ at $37 \mathrm{C}$. $50 \mu \mathrm{L}$ of $10 \%$ SDS was then added to stop the MTT reaction and inactivate the virus for analysis. Inactivation was allowed to proceed for $18 \mathrm{~h}$ at room temperature. After inactivation, the MTT colorimetric signal was analyzed using a Spectramax M5 plate reader.

\section{hCoV-229E Inhibition via Plaque Reduction Assay}

MRC-5 cells were seeded in 24 -well plates at $1 \times 10^{5}$ cells per well $24 \mathrm{~h}$ before the experiment. Polymer/siRNA complexes or PLANAs were prepared to deliver $100 \mathrm{nM}$ of siRNA targeting mRNA sequence for spike protein expression, $100 \mathrm{nM}$ of siRNA targeting mRNA sequence for envelope protein, or a combination of $50 \mathrm{nM}$ of each siRNA and were added to the wells one hour prior to infection. 5-fold dilutions of p3 229E virus stock in $500 \mu \mathrm{L}$ of serum-free DMEM were then added in triplicate such that, for each treatment condition, three wells were infected at $\operatorname{TCID}_{50} 8,1.6,0.32$, and Mock (no virus). After one hour of infection at $37 \mathrm{C}$, overlay media containing $1 \%$ Agarose in DMEM was heated to $50 \mathrm{C}$. Immediately prior to overlay, $4 \%$ FBS was added to the overlay media, $500 \mu \mathrm{L}$ of overlay was added to each well, and plates were cultured for 4 days at $37 \mathrm{C}, 5 \% \mathrm{CO}_{2}$. At $4 \mathrm{dpi}$, wells were fixed by adding $1 \mathrm{ml}$ of $10 \%$ formaldehyde and incubating at $37 \mathrm{C}$ overnight. After fixation, media was removed, and monolayers were stained with $1 \%$ crystal violet in $20 \%$ ethanol for $15 \mathrm{~min}$ at room temperature, followed by several rinses with $\mathrm{diH} 2 \mathrm{O}$ and drying before plaques were counted.

\section{Statistical Analysis}

Student $t$-test (two-ways, Unequal variance) was used in mean comparisons between two groups (e.g., the toxicity of each delivery system compared to the no treatment group). Oneway ANOVA with Tukey as Post Hoc test and significance level of 0.05 was used for statistical analysis of means between multiple groups (e.g., the cellular internalization for different carriers).

\section{RESULTS AND DISCUSSION}

\section{Cytotoxicity}

The toxicity of the siRNA delivery system plays a crucial role in the safety profile of this approach in a clinical setting. Since the proposed approach could potentially be used via the inhalation route, especially in the early stages of the SARS-CoV-2 infection, we selected MRC-5 human lung fibroblast cells for our toxicity experiments. The cell viability results after $24 \mathrm{~h}$ exposure to different carriers are summarized in Figure 1. While Lipofectamine $^{\mathrm{TM}}$ (added to the study design as a commercially available siRNA carrier) showed a drop in cell viability at $100 \mathrm{nM}$ of siRNA concentration ( $\sim 67 \%$ viability after $24 \mathrm{~h}$ exposure), neither the polymer complexes nor the PLANA formulation showed a cell viability of less than $85 \%$ at this siRNA concentration. The cell viability was not $<100 \%$ for the PLANA formulation at both siRNA concentrations.

The toxicity of siRNA delivery systems has been a limiting factor for their clinical use as well as extensive applications in vitro. For instance, the more efficient polymeric carriers are often cytotoxic (Wightman et al., 2001; Whitehead et al., 2009; Aliabadi et al., 2011; Aliabadi et al., 2012). Also, while positively charged lipids are usually more efficient in siRNA delivery than neutral lipids, they are also more toxic (Xue et al., 2015; Lechanteur and et al., 2018). We have previously reported on the cytotoxicity of similar lipopolymer/siRNA complexes with breast cancer cell lines (Aliabadi et al., 2011; Aliabadi et al., 2020) and primary human cells (Landry et al., 2016; ValenciaSerna et al., 2019). We also reported cytotoxicity of different PLANA formulations in MDA-MB-231 triple-negative human breast cancer cells, as well as a variety of non-tumorigenic cell lines, including myocardium cells and hepatocytes (Hall et al., 2021b). Those studies also demonstrated a negligible effect of the selected PLANA formulation (cited as formulation D incorporating LP-C18) on cell viability up to $100 \mathrm{nM}$ of siRNA concentrations. 


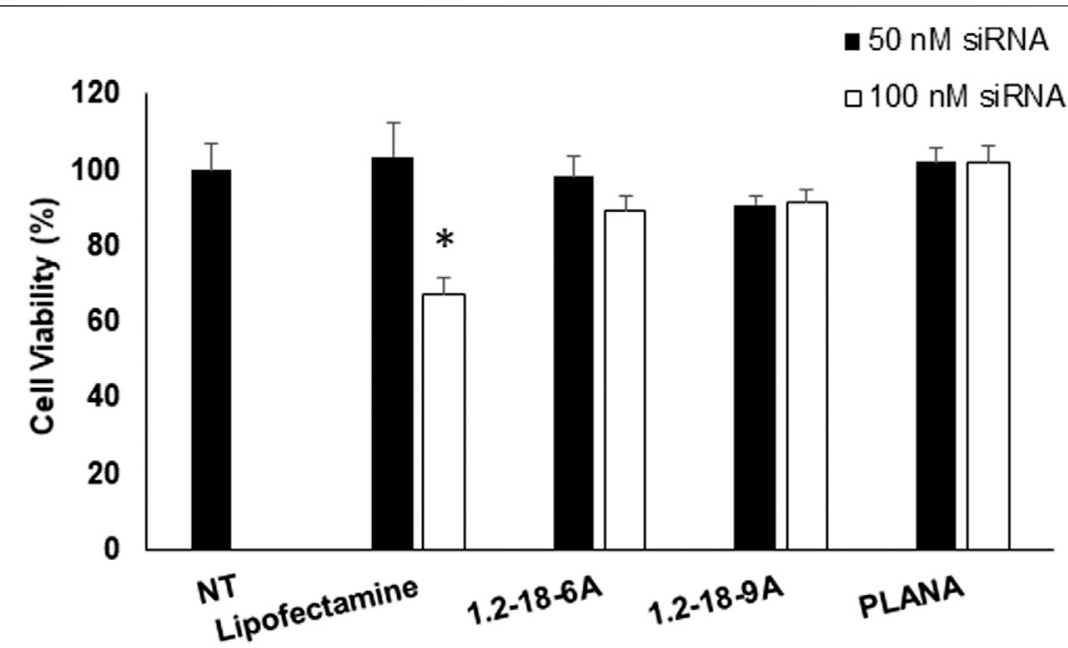

FIGURE 1 | The cytotoxicity of the selected siRNA/carriers in human MRC-5 lung fibroblast cells quantified using the CCK assay. No statistically significant difference was observed in the viability of cells exposed to either of the polyplexes or PLANA compared to cells exposed to normal saline (No Treatment, or NT). * indicates that the viability of the cells exposed to $100 \mathrm{nM}$ of siRNA delivered with Lipofectamine ${ }^{\mathrm{TM}}$ was significantly lower compared to NT group.

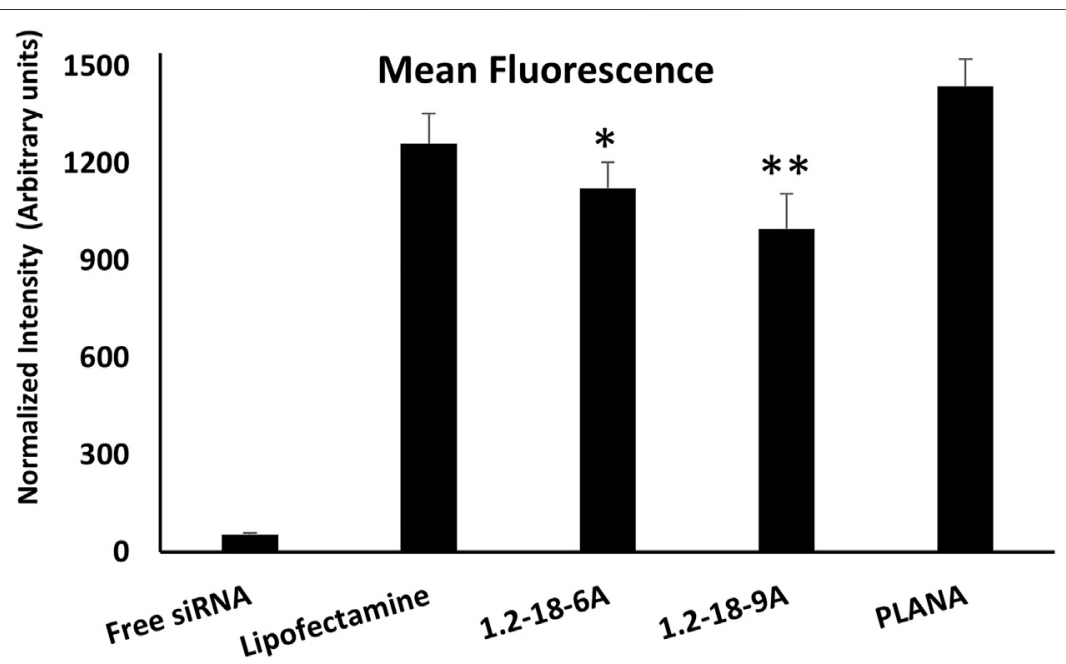

FIGURE 2 | The level of cellular internalization of AlexaFluor488-labeled siRNA in human MRC-5 cells using the selected carriers. All Selected delivery systems included in the study created mean fluorescence values comparable to Lipofectamine ${ }^{\mathrm{TM}}$ (included as positive control). * indicates statistically significant difference with PLANA group $(\alpha=0.013) .{ }^{* \star}$ indicates significant difference with both PLANA $(\alpha=0.002)$ and LipofectamineTM $(\alpha=0.034)$ groups. One-way ANOVA was used for statistical analysis.

\section{Cellular Internalization}

Internalization of free siRNA without a carrier into target cells is usually negligible, which is observed in our experiments as well (Figure 2). Lipofectamine ${ }^{\mathrm{TM}}$ increased the internalization of siRNA into MRC-5 significantly, as expected. The mean fluorescence observed in cells exposed to AF488-siRNA-encapsulated PLANA was higher than the fluorescence observed in Lipofectamine ${ }^{\mathrm{TM}}$ group (1437 vs. 1260); however, the difference was not statistically significant (one-way ANOVA; $\alpha=0.157$ ). The two polymers 12 $18-6 \mathrm{~A}$ and $12-18-9 \mathrm{~A}$ included in the study gave siRNA uptake that was comparable to Lipofectamine ${ }^{\mathrm{TM}}$. However, the difference in internalization between the polymer groups and Lipofectamine ${ }^{\mathrm{TM}}$ group was statistically significant ( $\alpha=0.034$; Figure 2).
The cellular internalization was visualized using confocal microscopy and the results were confirmed by flow cytometry (Figure 3). The effective internalization of fluorescent-labeled siRNA can be observed for both Lipofectamine and PLANA groups, where the AlexaFluor488-labeled siRNA were mostly confined to the cytoplasmic component (lipopolymers were not used in this study). Cellular internalization is one of the major characteristics indicating the efficiency of a siRNA carrier (along with protein silencing). Many different carriers have shown efficient cellular internalization in vitro; however, the level of internalization is usually dependent on the cell type and not universal in a wide spectrum of cell lines. We previously reported encapsulation efficiency, protection against enzymatic degradation, and efficient 


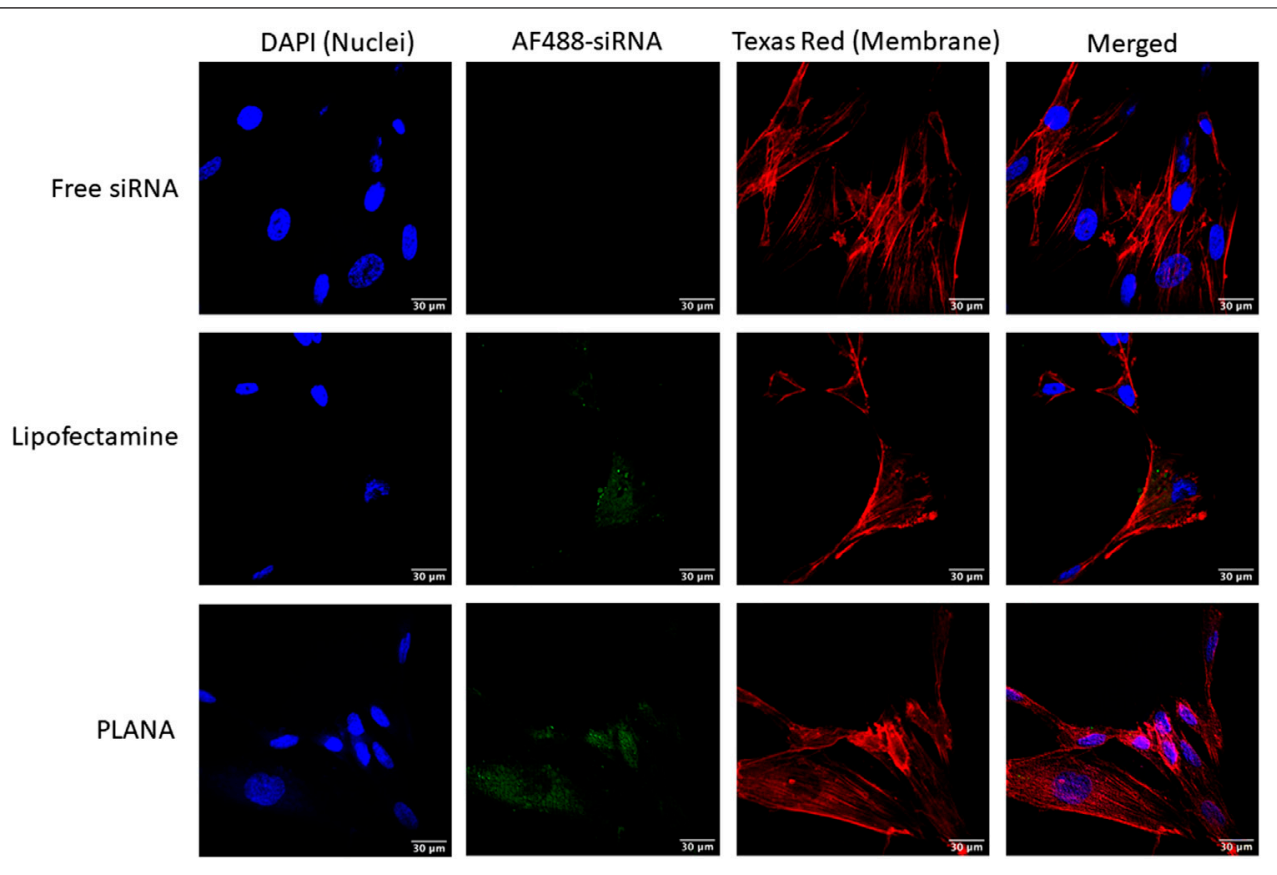

FIGURE 3 | The confocal microscopy images of AF488-labeled siRNA (green channel) delivered to MRC-5 cells by Lipofectamine and PLANAs as compared to free AF488-labeled siRNA. DAPI (blue channel) and Texas Red (Red channel) were used to dye the nuclei and cell membranes, respectively.

cellular uptake of siRNA formulated with PLANAs, which demonstrated $>98 \%$ encapsulation efficiency and should high stability in the invitro studies (Hall et al., 2021a). The release profile of this formulation (tested by dialysis method vs. DI water as receiving phase) showed $\sim 20$ and 38\% siRNA release after 24 and $72 \mathrm{~h}$. The release in the cytoplasm is expected to be much faster due to dissociation of the nanoparticles as a result of dilution and/or displacement by other negatively charged components inside the cells. Leu-Fect B reagent have also shown near complete encapsulation and protection against enzymatic degradation for at least $24 \mathrm{~h}$ (information provided by the supplier). We also have reported the internalization of fluorescence-labeled siRNA in MDA-MB-231 triple-negative breast cancer cell lines, where we observed the most efficient cellular internalization for PLANA D formulation (the selected composition for the present study), which showed comparable cellular uptake to Lipofectamine ${ }^{\mathrm{TM}}$ (Hall et al., 2021a). This confirms efficient cellular internalization into human lung fibroblast cells, which are the target cells for the purpose of this study.

\section{Antiviral Effect}

We assessed the viability of viral transduced cells and plaque formation to determine the effect of siRNA delivery in inhibiting viral infection on MRC-5 cells. The viability of healthy and hCoV-229E-infected MRC-5 cells was evaluated using the MTT assay after siRNA delivery targeting S-protein, E-protein, or a combination of both (each representing half of the concentration compared to individual siRNA groups) in a variety of concentrations (ranging from 25 to $100 \mathrm{nM}$ of total siRNA). The untreated MRC- 5 cells were included to confirm the safety profile observed in cytotoxicity studies when siRNAs were delivered to the cells. Remdesivir was used as the positive control in this set of studies.

The siRNA delivery (in the absence of viral infection) did not affect the cell viability significantly, which again confirmed the minimal cytotoxicity of the siRNA treatments on the lung cells. The lowest viability observed in the normal MRC- 5 cells was in the cells exposed to E-protein siRNA lipopolyplex ( $~ 81$ and $\sim 89 \%$ viability for $100 \mathrm{nM}$ of siRNA delivered by $1.2-18-6 \mathrm{~A}$ and $1.2-18$ 9A, respectively: Figure 4). Infecting MRC-5 cells with hCoV$229 \mathrm{E}$ decreased the viability to $\sim 21 \%$, clearly indicating the cytopathic effect of hCoV-229E infection on MRC-5 cells. In hCoV-229E-infected cells, delivering S-protein targeting siRNA preserved cell viability to 80,79 , and $88 \%$ with $100 \mathrm{nM}$ siRNA delivered by $12-18-6 \mathrm{~A}, 12-18-9 \mathrm{~A}$, and PLANAs, respectively. Targeting E-protein was less effective in preserving cell viability for all selected delivery systems $(54,45$, and $50 \%$ cell viability with $100 \mathrm{nM}$ siRNA delivered by $12-18-6 \mathrm{~A}, 12-18-9 \mathrm{~A}$, and PLANAs, respectively). Silencing S-protein and E-protein simultaneously (50 $\mathrm{nM}$ for each siRNA) completely restored cell viability for all three delivery systems. When at $50 \mathrm{nM}$ siRNA combinations ( $25 \mathrm{nM}$ of each siRNA), cell viability was increased to $90-100 \%$ for $12-18-6 \mathrm{~A}, 12-18-9 \mathrm{~A}$, and PLANAs. Treating the hCoV-229E-infected MRC- 5 cells with $5 \mu \mathrm{M}$ remdesivir restored the viability to $92 \%$ (Figure 4D).

The efficiency of the reported approach should be additionally evaluated by quantifying the viral RNA load in infected cells using real-time PCR. However, we demonstrated effective internalization of siRNA in MRC- 5 cells in this manuscript and have previously reported the silencing efficiency of the selected delivery systems in different cell lines after delivering the siRNA cargo to the cytoplasm (Aliabadi et al., 2020; Hall et al., 2021a; Plianwong 

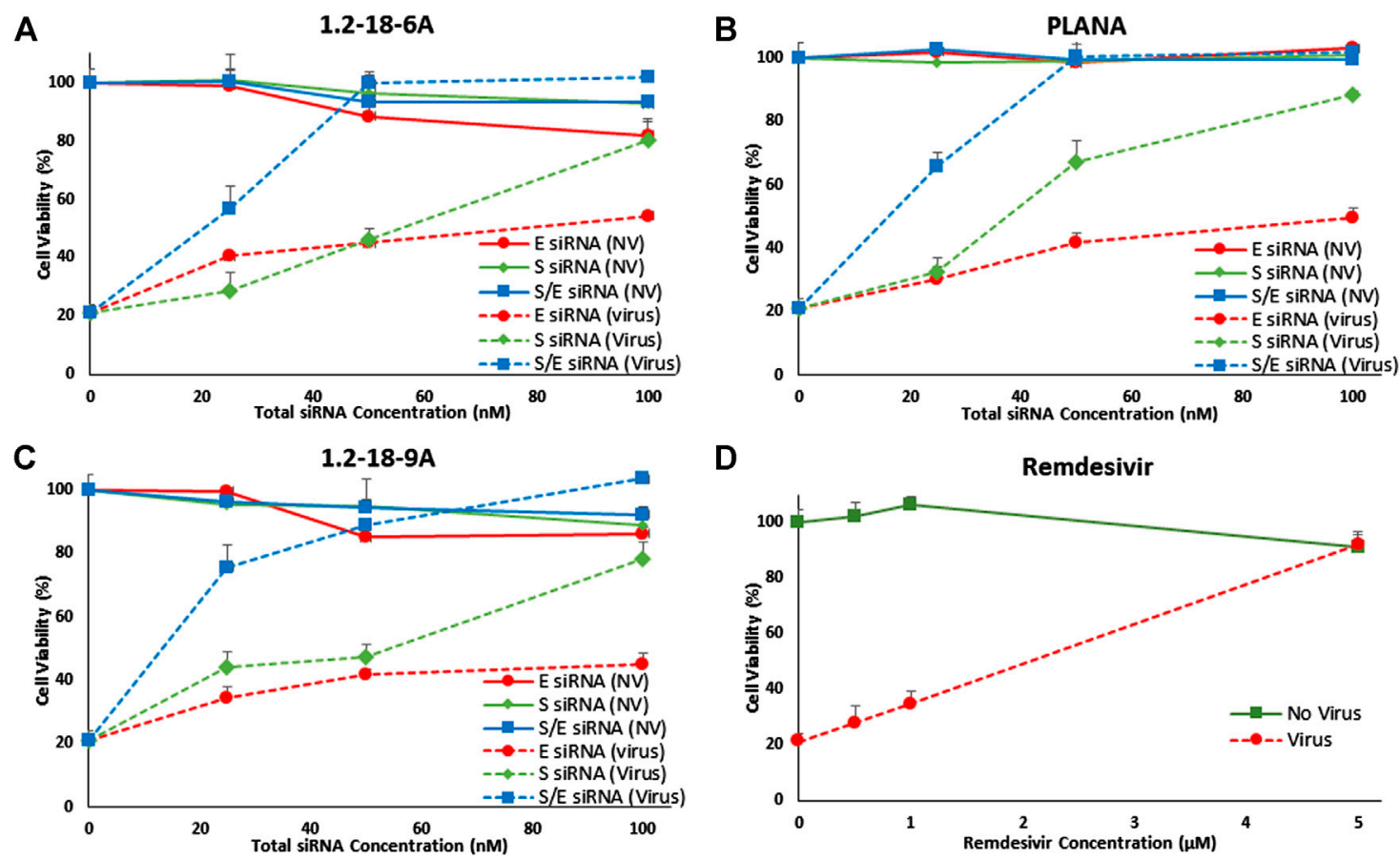

FIGURE 4 | Cell viability of healthy (no virus or NV) and hCoV-229E-infected (Virus) MRC-5 cells after delivering 25, 50, and 100 nM of siRNA targeting Spike (S), Envelope (E), or a combination of both siRNAs (1:1 ratio) using 12-18-6A (A), 1.2-18-9A (B), PLANAs (C), plus remdesivir as positive control (D). Infecting the cells with $\mathrm{hCoV}-229 \mathrm{E}$ diminished the cell viability to $21 \%$ (viability at $0 \mathrm{nM}$ siRNA). While delivering S or E targeting siRNA restored the cell viability, delivering the combination of the siRNAs completely preserved cell viability, even at $50 \mathrm{nM}$ total siRNA concentration.
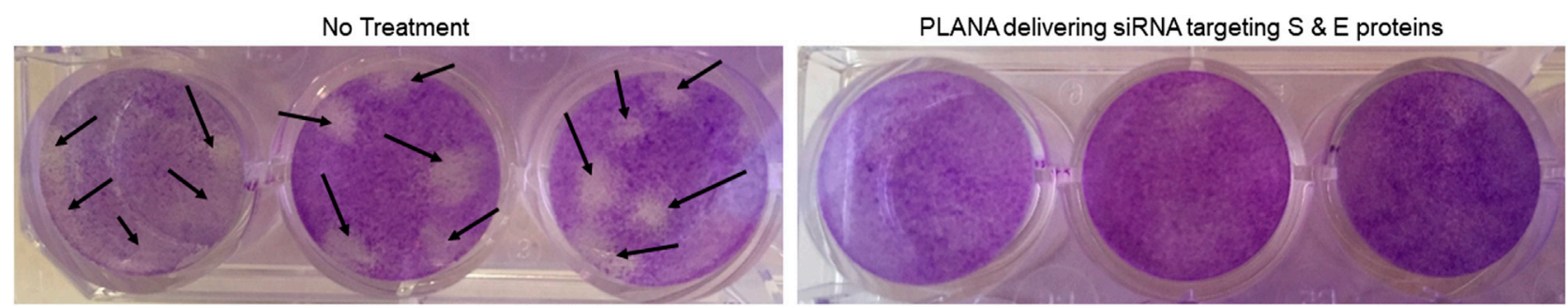

FIGURE 5 | Targeting S-protein and E-protein via PLANAs completely eliminated plaques seen at 8 TCID $_{50}$ units per well in no treatment group (black arrows). Experiments were conducted in triplicates.

et al., 2020). Also, the increase in the functional outcome of siRNA treatment in restoring the cell viability with increasing siRNA concentration presents a dose-response effect in line with the expected direct causal relationship.

Finally, we used plaque assay to confirm the efficiency of the siRNA approach in preventing plaques formed in MRC-5 monolayers as a result of hCoV-229E-infection. The plaque reduction neutralization test (PRNT) is considered a "gold standard" in the evaluation of antiviral strategies used against SARS-CoV-2 infections (Padoan et al., 2020; Perera et al., 2020; Xie et al., 2020) and other viral infections (McLaughlin et al., 2020; Yau et al., 2020). Using the PLANA-delivered combination of siRNAs targeting S-protein and E-protein completely eliminated plaques that were observed in non-treated cell cultures (Figure 5).

The deployment of the siRNA as an alternative approach to upper respiratory tract viral infections is not unprecedented.
Many manuscripts reviewed the possibility of using RNA interference (RNAi) as a therapeutic approach against COVID19 (Itani et al., 2020; Le et al., 2020; Piyush et al., 2020; Shaffer, 2020; Yu et al., 2020). We also reviewed the siRNA-based strategies used in the past coronavirus infections and the prospects of such strategies in combating SARS-CoV-2 pandemic (Uludağ et al., 2020). A recent paper by Lundstrom has also reviewed viral vectors in delivering other RNA interference mediators (e.g., shRNA) as a therapeutic approach in a variety of viral infections (Lundstrom, 2020). Since the start of pandemic in 2019, pharmaceutical companies are also exploring this approach as a therapy against SARS-CoV-2 infection, and publications in this regard are expected to appear soon. We previously reported siRNA delivery by the lipopolymers as an effective approach in several cancer models [reviewed in (Bahadur K.C. et al., 2017) and (Landry et al., 2015)] and recently shown 
PLANAs to be effective in silencing two model proteins (Src and kinase RPS6KA5) in MDA-MB-231 breast cancer cells (Hall et al., 2021b).

In conclusion, we showed the efficiency of an siRNA-based anti-viral approach in vitro in eliminating the damage caused in MRC-5 lung fibroblast cells by hCoV-229E-infection. We are currently exploring the efficiency of this approach in vitro and in vivo against SARS-CoV-2 infection. As a treatment in a clinical setting, the siRNA would be delivered after the infection occurred, while we implemented the siRNA treatment at the same time as virus infection in this study. However, due to the high viral load used in the viability test approach (to complete the study in a reasonable timeframe), handling the infection would be more difficult if the siRNA was introduced after the viral replication (note that the plaque test used here is performed using a lower viral load to avoid complete eradication of the cell monolayer). While this approach can be designed as a preventive measure to slow the spread of the virus infection, we would implement a more clinically relevant approach in animal studies, where the siRNA administration would start after animal model is infected. Although the challenges facing systemic delivery of siRNA have slowed extensive use of RNAibased therapeutics in clinics, delivering siRNA via inhalation route could be a simpler alternative in the treatment of COVID19 patients. In order to ensure safety and efficiency of this approach via inhalation route, however, we are designing experiments in human bronchial epithelial cells using a model reported previously by Wang et al. (2000).

\section{DATA AVAILABILITY STATEMENT}

The raw data supporting the conclusions of this article will be made available by the authors, without undue reservation.

\section{REFERENCES}

Aliabadi, H. M., Landry, B., Bahadur, R. K., Neamnark, A., Suwantong, O., and Uludağ, H. (2011). Impact of Lipid Substitution on Assembly and Delivery of siRNA by Cationic Polymers. Macromol. Biosci. 11 (5), 662-672. doi:10.1002/ mabi.201000402

Aliabadi, H. M., Landry, B., Sun, C., Tang, T., and Uludağ, H. (2012). Supramolecular Assemblies in Functional siRNA Delivery: where Do We Stand?. Biomaterials 33 (8), 2546-2569. doi:10.1016/j.biomaterials.2011.11.079

Aliabadi, H. M., Maranchuk, R., Kucharski, C., Mahdipoor, P., Hugh, J., and Uludağ, H. (2013). Effective Response of Doxorubicin-Sensitive and -resistant Breast Cancer Cells to Combinational siRNA Therapy. J. Controlled Release 172 (1), 219-228. doi:10.1016/j.jconrel.2013.08.012

Aliabadi, H. M., Bahadur K.C., R., Bousoik, E., Hall, R., Barbarino, A., Thapa, B., et al. (2020). A Systematic Comparison of Lipopolymers for siRNA Delivery to Multiple Breast Cancer Cell Lines: In vitro Studies. Acta Biomater. 102, 351-366. doi:10.1016/j.actbio.2019.11.036

Bahadur K.C., R., Thapa, B., Velencia-Serna, J., Aliabadi, H. M., and Uludağ, H. (2017). Nucleic Acid Combinations: A New Frontier for Cancer Treatment. J. Control. Release 256, 153-169. doi:10.1016/j.jconrel.2017.04.029

Cavalcanti, A. B., Zampieri, F. G, Rosa, R. G, Azevedo, L. C. P, Veiga, V. C, Avezum, A, et al. (2020). Hydroxychloroquine with or without Azithromycin in MildTo-Moderate Covid-19. N. Engl. J. Med. 383 (21), 2041-2052. doi:10.1056/ NEJMoa2019014

\section{AUTHOR CONTRIBUTIONS}

The study design was a collaboration among HMA, HU, and KP. The experimental methods were mostly performed by PM. The viral infection experiments were designed and performed by JT. Data analysis was performed as a collaboration among HMA, HU, and KP. Manuscript was written by HMA, and was revised and modified by $\mathrm{HU}$ and KP.

\section{FUNDING}

This study was partially supported by a Research Starter Grant in Pharmaceutics from PhRMA Foundation. The authors would also like to thank Chapman University School of Pharmacy for the financial support provided to graduate students and Faculty. Additional funding was provided by the Natural Sciences and Engineering Research Council of Canada (NSERC; Uludag Lab).

\section{ACKNOWLEDGMENTS}

We thank Remant K.C. for the preparation of the Leu-Fect B materials used in this study. $\mathrm{HU}$ is a shareholder in $\mathrm{RJH}$ Biosciences Inc., which provided materials for this study, and declare the financial conflict of interests due to ownership in $\mathrm{RJH}$ Biosciences Inc.

\section{SUPPLEMENTARY MATERIAL}

The Supplementary Material for this article can be found online at: https://www.frontiersin.org/articles/10.3389/fnano.2021.670543/ full\#supplementary-material

Do, H., Sharma, M., El-Sayed, N. S., Mahdipoor, P., Bousoik, E., Parang, K., et al. (2017). Difatty Acyl-Conjugated Linear and Cyclic Peptides for siRNA Delivery. ACS Omega 2 (10), 6939-6957. doi:10.1021/acsomega.7b00741

Gordon, D. E., Jang, G. M., Bouhaddou, M., Xu, J., Obernier, K., and O’Meara, M. J. (2020). A SARS-CoV-2-Human Protein-Protein Interaction Map Reveals Drug Targets and Potential Drug-Repurposing. bioRxiv.

Hall, R., Alasmari, A., Mozaffari, S., Mahdipoor, P., Parang, K., and Montazeri Aliabadi, H. (2021a). Peptide/Lipid-Associated Nucleic Acids (PLANAs) as a Multicomponent siRNA Delivery System. Mol. Pharm. 18 (3), 986-1002. doi:10.1021/acs.molpharmaceut.0c00969

Hall, R., Alasmari, A., Mozaffari, S., Mahdipoor, P., Parang, K., Aliabadi, H. M., et al. (2021b). Peptide/Lipid-Associated Nucleic Acids (PLANAs) as a Multicomponent siRNA Delivery System. Mol. Pharm. 18 (3), 986-1002. doi:10.1021/acs.molpharmaceut.0c00969

Itani, R., Tobaiqy, M., and Al Faraj, A. (2020). Optimizing Use of Theranostic Nanoparticles as a Life-Saving Strategy for Treating COVID-19 Patients. Theranostics 10 (13), 5932-5942. doi:10.7150/thno.46691

Landry, B., Valencia-Serna, J., Gul-Uludag, H., Jiang, X., Janowska-Wieczorek, A., Brandwein, J., et al. (2015). Progress in RNAi-Mediated Molecular Therapy of Acute and Chronic Myeloid Leukemia. Mol. Ther. Nucleic Acids 4, e240. doi:10. 1038/mtna.2015.13

Landry, B., Gül-Uludağ, H., Plianwong, S., Kucharski, C., Zak, Z., Parmar, M. B., et al. (2016). Targeting CXCR4/SDF-1 axis by Lipopolymer Complexes of siRNA in Acute Myeloid Leukemia. J. Controlled Release 224, 8-21. doi:10. 1016/j.jconrel.2015.12.052 
Le, T. K., Paris, C., Khan, K. S., Robson, F., Ng, W-L., and Rocchi, P. (2020). Nucleic Acid-Based Technologies Targeting Coronaviruses. Trends Biochem. Sci. S0968-0004 (20), 30295-4. doi:10.1016/j.tibs.2020.11.010

Lechanteur, A., Sanna, V., Duchemin, A., Evrard, B., Mottet, D., Piel, G., et al. (2018). Cationic Liposomes Carrying siRNA: Impact of Lipid Composition on Physicochemical Properties, Cytotoxicity and Endosomal Escape. Nanomaterials (Basel) 8 (5), 270. doi:10.3390/nano8050270

Li, B.-j., Tang, Q., Cheng, D., Qin, C., Xie, F. Y., Wei, Q., et al. (2005). Using siRNA in Prophylactic and Therapeutic Regimens against SARS Coronavirus in Rhesus Macaque. Nat. Med. 11 (9), 944-951. doi:10.1038/nm1280

Lundstrom, K. (2020). Are Viral Vectors Any Good for RNAi Antiviral Therapy? Viruses 12 (10), 1189. doi:10.3390/v12101189

Lyngbakken, M. N., Berdal, J-E., Eskesan, A., Kvale, D., Olsen, I. C., Rueegg, C. S., et al. (2020). A Pragmatic Randomized Controlled Trial Reports Lack of Efficacy of Hydroxychloroquine on Coronavirus Disease 2019 Viral Kinetics. Nat. Commun. 11 (1), 5284. doi:10.1038/s41467-020-19056-6

McLaughlin, M. M., Ma, Y., Scherzer, R., Rahalkar, S., Martin, J. N., Mills, C., et al. (2020). Association of Viral Persistence and Atherosclerosis in Adults with Treated HIV Infection. JAMA Netw. Open 3 (10), e2018099. doi:10.1001/ jamanetworkopen.2020.18099

Meng, B., Lui, Y.-w., Meng, S., Cao, C., and Hu, Y. (2006). Identification of Effective siRNA Blocking the Expression of SARS Viral Envelope E and RDRP Genes. Mol Biotechnol 33 (2), 141-148. doi:10.1385/mb:33:2:141

Mozaffari, S., Bousoik, E., Amirrad, F., Lamboy, R., Coyle, M., Hall, R., et al. (2019). Amphiphilic Peptides for Efficient siRNA Delivery. Polymers (Basel) 11 (4), 703. doi:10.3390/polym11040703

Padoan, A., Bonfante, F., Pagliari, M., Bortolami, A., Negrini, D., Zuin, S., et al. (2020). Analytical and Clinical Performances of Five Immunoassays for the Detection of SARS-CoV-2 Antibodies in Comparison with Neutralization Activity. EBioMedicine 62, 103101. doi:10.1016/j.ebiom. 2020.103101

Perera, R. APM., Ko, R., Tsang, O. TY., Hui, D. SC, Kwan, M. YM., Brackman, C. J., et al. (2020). Evaluation of a SARS-CoV-2 Surrogate Virus Neutralization Test for Detection of Antibody in Human, Canine, Cat and Hamster Sera. J. Clin. Microbiol. 59 (2), e02504-20. doi:10.1128/JCM.02504-20

Piyush, R., Rajarshi, K., Chatterjee, A., Khan, R., and Ray, S. (2020). Nucleic AcidBased Therapy for Coronavirus Disease 2019. Heliyon 6 (9), e05007. doi:10. 1016/j.heliyon.2020.e05007

Plianwong, S., Thapa, B., Remant Bahadur, K.c., Kucharski, S., Rojanarata, T., and Uludağ, H. (2020). Enabling Combinatorial siRNA Delivery against ApoptosisRelated Proteins with Linoleic Acid and Alpha-Linoleic Acid Substituted Low Molecular Weight Polyethylenimines. Pharm. Res. 37 (3), 46. doi:10.1007/ s11095-020-2770-9

Qin, Z.-l., Zhao, P., Zhang, X.-1., Yu, J.-g., Cao, M.-m., Zhao, L.-j., et al. (2004). Silencing of SARS-CoV Spike Gene by Small Interfering RNA in HEK 293T Cells. Biochem. Biophysical Res. Commun. 324 (4), 1186-1193. doi:10. 1016/j.bbrc.2004.09.180

Qin, Z.-l., Zhao, P., Cao, M.-m., and Qi, Z.-t. (2007). siRNAs Targeting Terminal Sequences of the SARS-Associated Coronavirus Membrane Gene Inhibit M Protein Expression through Degradation of M mRNA. J. Virol. Methods 145 (2), 146-154. doi:10.1016/j.jviromet.2007.05.017

Raabe, T., Schelle-Prinz, B., and Siddell, S. G. (1990). Nucleotide Sequence of the Gene Encoding the Spike Glycoprotein of Human Coronavirus HCV 229E. J. Gen. Virol. 71 (Pt 5), 1065-1073. doi:10.1099/0022-1317-71-5-1065

Shaffer, C. (2020). Mist Begins to Clear for Lung Delivery of RNA. Nat. Biotechnol. 38 (10), 1110-1112. doi:10.1038/s41587-020-0692-z

Spinner, C. D., Gottlieb, R. L., Criner, G. J., Arribas López, J. R., Cattelan, A. M., Soriano Viladomiu, A., et al. (2020). Effect of Remdesivir vs Standard Care on Clinical Status at 11 Days in Patients with Moderate COVID-19. JAMA 324 (11), 1048-1057. doi:10.1001/jama.2020.16349

Tang, Q., Li, B., Woodle, M., and Lu, P. Y. (2008). Application of siRNA against SARS in the Rhesus Macaque Model. Methods Mol. Biol. 442, 139-158. doi:10. 1007/978-1-59745-191-8_11

U.S. Food and Drug Administration Approves Gilead's Antiviral Veklury ${ }^{\circledR}$ (Remdesivir) for Treatment Of COVID-19 2020. Available from: https://www.fda.gov/news-events/ press-announcements/fda-approves-first-treatment-covid-19.
Uludăg, H., Parent, K., Aliabadi, H. M., and Haddadi, A. (2020). Prospects for RNAi Therapy of COVID-19. Front. Bioeng. Biotechnol. 8, 916. doi:10.3389/ fbioe.2020.00559

Valencia-Serna, J., Kucharski, C., Chen, M., Kc, R., Jiang, X., Brandwein, J., et al. (2019). siRNA-Mediated BCR-ABL Silencing in Primary Chronic Myeloid Leukemia Cells Using Lipopolymers. J. Controlled Release 310, 141-154. doi:10.1016/j.jconrel.2019.08.018

Wang, G., Deering, C., Macke, M., Shao, J., Burns, R., Blau, D. M., et al. (2000). Human Coronavirus 229E Infects Polarized Airway Epithelia from the Apical Surface. J. Virol. 74 (19), 9234-9239. doi:10.1128/jvi.74.19.92349239.2000

Wang, Y., Zhang, D., Du, G., Du, R., Zhao, J., Jin, Y., et al. (2020). Remdesivir in Adults with Severe COVID-19: a Randomised, Double-Blind, PlaceboControlled, Multicentre Trial. Lancet 395 (10236), 1569-1578. doi:10.1016/ S0140-6736(20)31022-9

Whitehead, K. A., Langer, R., and Anderson, D. G. (2009). Knocking Down Barriers: Advances in siRNA Delivery. Nat. Rev. Drug Discov. 8 (2), 129-138. doi: $10.1038 / \mathrm{nrd} 2742$

Wightman, L., Kircheis, R., Rössler, V., Carotta, S., Ruzicka, R., Kursa, M., et al. (2001). Different Behavior of Branched and Linear Polyethylenimine for Gene Deliveryin Vitro Andin Vivo. J. Gene Med. 3 (4), 362-372. doi:10.1002/ jgm. 187

Wu, C.-J., Huang, H.-W., Liu, C.-Y., Hong, C.-F., and Chan, Y.-L. (2005). Inhibition of SARS-CoV Replication by siRNA. Antiviral Res. 65 (1), 45-48. doi:10.1016/j.antiviral.2004.09.005

Xie, X., Muruato, A. E., Zhang, X., Lokugamage, K.G., Fontes-Garfias, C.R., Jing, Z., et al. (2020). A Nanoluciferase SARS-CoV-2 for Rapid Neutralization Testing and Screening of Anti-infective Drugs for COVID-19. Nat. Commun. 11 (1), 5214. doi:10.1038/s41467-020-19055-7

Xue, H., Guo, P., Wen, W.-C., and Wong, H. (2015). Lipid-Based Nanocarriers for RNA Delivery. Curr Pharm Des 21 (22), 3140-3147. doi:10.2174/ 1381612821666150531164540

Yau, C., Gan, E. S., Kwek, S. S., Tan, H. C., Ong, E. Z., Hamis, N. Z., et al. (2020). Live Vaccine Infection Burden Elicits Adaptive Humoral and Cellular Immunity Required to Prevent Zika Virus Infection. EBioMedicine 61, 103028. doi:10.1016/j.ebiom.2020.103028

Yu, A.-M., Choi, Y. H., and Tu, M.-J. (2020). RNA Drugs and RNA Targets for Small Molecules: Principles, Progress, and Challenges. Pharmacol. Rev. 72 (4), 862-898. doi:10.1124/pr.120.019554

Zhang, Y., Li, T., Fu, L., Yu, C., Li, Y., Xu, X., et al. (2004). Silencing SARS-CoV Spike Protein Expression in Cultured Cells by RNA Interference. FEBS Lett. 560 (1-3), 141-146. doi:10.1016/s0014-5793(04)00087-0

Zhang, R., Wang, K., Lv, W., Yu, W., Xie, S., Xu, K., et al. (2014). The ORF4a Protein of Human Coronavirus 229E Functions as a Viroporin that Regulates Viral Production. Biochim. Biophys. Acta. 1838 (4), 1088-1095. doi:10.1016/j. bbamem.2013.07.025

Zhao, P., Qin, Z.-L., Ke, J.-S., Lu, Y., Liu, M., Pan, W., et al. (2005). Small Interfering RNA Inhibits SARS-CoV Nucleocapsid Gene Expression in Cultured Cells and Mouse Muscles. FEBS Lett. 579 (11), 2404-2410. doi:10.1016/j.febslet.2005. 02.080

Conflict of Interest: Author HU is a shareholder in RJH Biosciences Inc. which had the following involvement with the study: RJH Biosciences Inc. provided materials for this study.

The remaining authors declare that the research was conducted in the absence of any commercial or financial relationships that could be construed as a potential conflict of interest.

Copyright $\odot 2021$ Montazeri Aliabadi, Totonchy, Mahdipoor, Parang and Uludağ. This is an open-access article distributed under the terms of the Creative Commons Attribution License (CC BY). The use, distribution or reproduction in other forums is permitted, provided the original author(s) and the copyright owner(s) are credited and that the original publication in this journal is cited, in accordance with accepted academic practice. No use, distribution or reproduction is permitted which does not comply with these terms. 